\title{
An in situ sample environment reaction cell for spatially resolved x-ray absorption spectroscopy studies of powders and small structured reactors
}

\author{
Chu Zhang, ${ }^{1}$ Johan Gustafson, ${ }^{1}$ Lindsay R. Merte, ${ }^{1}$ Jonas Evertsson, ${ }^{1}$ \\ Katarina Norén, ${ }^{2}$ Stefan Carlson, ${ }^{2}$ Håkan Svensson, ${ }^{2}$ and Per-Anders Carlsson ${ }^{3}$ \\ ${ }^{1}$ Division of Synchrotron Radiation Research, \\ Lund University, \\ Box 118, SE-221 00, Sweden \\ ${ }^{2}$ MAX IV Laboratory \\ Lund University, \\ Box 118, SE-221 00, Sweden \\ ${ }^{3}$ Competence Centre for Catalysis, Chalmers University of Technology, SE-412 96 Göteborg, Sweden
}

(Dated: March 6, 2015)

\begin{abstract}
An easy-to-use sample environment reaction cell for X-ray based in situ studies of powders and small structured samples, e.g., powder, pellet and monolith catalysts, is described. The design of the cell allows for flexible use of appropriate X-ray transparent windows, shielding the sample from ambient conditions, such that incident X-ray energies as low as $3 \mathrm{keV}$ can be used. Thus in situ X-ray absorption spectroscopy (XAS) measurements in either transmission or fluorescence mode are facilitated. Total gas flows up to about $500 \mathrm{ml}_{n} / \mathrm{min}$ can be fed while the sample temperature is accurately controlled (at least) in the range 25 to $500^{\circ} \mathrm{C}$. The gas feed is composed by a versatile gasmixing system and the effluent gas flow composition is monitored with mass spectrometry (MS). These systems are described briefly. Results from simultaneous XAS/MS measurements during oxidation of carbon monoxide over a $4 \% \mathrm{Pt} / \mathrm{Al}_{2} \mathrm{O}_{3}$ powder catalyst are used to illustrate the system performance in terms of transmission XAS. Also $2.2 \% \mathrm{Pd} / \mathrm{Al}_{2} \mathrm{O}_{3}$ and $2 \% \mathrm{Ag}-\mathrm{Al}_{2} \mathrm{O}_{3}$ powder catalysts have been used to demonstrate X-ray absorption near-edge structure (XANES) spectroscopy in fluorescence mode. Further a $2 \% \mathrm{Pt} / \mathrm{Al}_{2} \mathrm{O}_{3}$ monolith catalyst was used ex situ for transmission XANES. The reaction cell opens for facile studies of structure-function relationships for model as well as realistic catalysts both in the form of powders, small pellets and coated or extruded monoliths at near realistic conditions. The applicability of the cell for X-ray diffraction measurements is discussed.
\end{abstract}

PACS numbers: Valid PACS appear here

\section{INTRODUCTION}

Within the broad field of material science particular attention is paid to atomic level understanding of physical and chemical properties of functional materials under relevant working conditions. Although "relevant" may vary depending on the goal at hand, the methodology whereby such knowledge can be achieved, generally, is to use so-called in situ or operando analysis [1]. Thereby the desired properties of a certain functional material are monitored while a given process is carried out. This type of correlation is often termed structure-function relationship and is crucial for knowledge-based development of new materials with improved functionality. Important cases in practice can be found in applications of, e.g., catalysis, electrochemistry, photovoltaics, corrosion, membranes and electronics [2]. The demonstration example used here is a gas-solid heterogeneous catalytic reaction, vis., oxidation of carbon monoxide over a platinum based powder catalyst, while an X-ray based spectroscopic measurement is carried out.

$\mathrm{X}$-rays are one among several probes that can be used to study electronic and atomic structure of materials $[1,3-5]$. Synchrotron radiation sources provide X-rays with high flux and brilliance and naturally X-ray based methods have in large parts been developed by scientists at or in close collaboration with these facilities $[4,5]$. When used as a photon in-photon out technique, as in Xray absorption spectroscopy (XAS) and X-ray diffraction (XRD), the weak interaction between X-rays and matter governs the in situ study of the properties of the (solid) material not only in vacuum but more importantly in the presence of a gas. This is typically the relevant case for a heterogeneous catalytic reaction. Despite this, many challenging design tasks remain and below some of these important aspects are discussed.

Over the years many sample environment reaction cells designed for in situ studies of working catalysts have been reported [4-17]. For an overview of the field see for example the reviews made by Newton et al. [4] and Bordiga et al. [5] and the references therein. The reported cell designs span a broad range, from quartz capillary microreactors to geometrically more advanced cells often developed with a certain purpose in mind [15], or for a multipurpose measurement with auxiliary spectroscopies [17]. However, it is clear that all cells have both advantages and disadvantages and there seems to be no cell that fits every purpose. In order to design an appropriate reaction cell, numerous aspects need to be considered. Alongside practical issues such as ease of use, mounting configuration and robustness, which should not be underestimated, one finds the X-ray energy range of inter- 
est and related to this the X-ray penetration depth and signal-to-noise ratio as well as the control of prevailing reaction conditions primarily flow dynamics and pressure of reactants, sample temperature and chemical stability (inertness) of the reactor surfaces that are exposed to the reactants [4]. It is not our intention to give a rich review here, however, a few examples on different types of reaction cells reported in the open literature may be appropriate.

One now almost classic example is the capillary microreactor developed by Clausen et al. $[7,18]$ that was used for quick extended X-ray absorption fine structure spectroscopy (QEXAFS) and XRD measurements on powder catalysts. In this design a powder catalyst is positioned between two pieces of quartz wool in a small quartz capillary tube with outer diameter of about 0.5 $\mathrm{mm}$ and wall thickness of $0.01 \mathrm{~mm}$. The capillary is connected to stainless steel tubes via standard Swagelok fittings and gases are introduced by a versatile gas-mixing system. The heating of the capillary occurs by streaming hot $\mathrm{N}_{2}$ gas over it and a Kapton ${ }^{\circledR}$ heat shield surrounding the capillary tube is used to ensure an isothermal sample. With this arrangement the sample temperature could be maintained at within $0.1 \mathrm{~K}$ from the set temperature. Bare et al. [16] reported on another lay-out where the catalyst sample is positioned inside a $280 \mathrm{~mm}$ long quartz tube with $17 \mathrm{~mm}$ inner diameter. The wall thickness is not given but is expected to be about 1-2 $\mathrm{mm}$ and thus this seems to be a more robust design as compared to capillary based systems. The middle part of the quartz tube is heated in an oven while the end parts, which are connected to stainless steel UHV Conflat ${ }^{\circledR}$ flanges, are outside and not heated. The flanges have two main functions: to hold the X-ray transparent windows, e.g., Kapton ${ }^{\circledR}$ windows that are glued onto them, and to allow gas flow in/out of the reactor tube via the double-sided flange. A drawback with the mentioned cells is the limitation to be used at elevated pressures. In such cases, as an example, stainless steel reactors with two Be windows for the transmission of the X-ray beam has been used for pressures up to 100 bar and temperature around $500^{\circ} \mathrm{C}[6,13]$. Other cells are designed to include on top of X-ray radiation and effluent analytics also complementary probes such as infrared radiation. For example Newton modified the commercial Spectratech cell to allow for XAS or XRD while simultaneously measuring with diffuse reflectance infrared Fourier transform spectroscopy (DRIFTS) and MS [19]. This cell has been successfully used to study, for example, the mechanisms behind oxidation of methane over supported catalysts under transient conditions $[20,21]$. In line with this, Chiarello et al. recently reported a novel cell also to be used for synchronous XAS/DRIFTS/MS [17]. This cell is considerably improved as compared to previous designs of such multi-purpose cells. The cell permits high quality infrared and x-ray spectroscopy thanks to a rather large infrared window with an inserted X-ray window. In terms of reactor design it is characterized as a plug-flow reactor with significantly reduced dead volume as compared to commercially available counterparts, which facilitates the use of transient experiments with high time-resolution.

In the present work we report on the design of an in situ sample environment reaction cell that allows for spatially resolved XAS of primarily powder catalysts and small structured catalytic reactors, i.e., pellets or monoliths. To demonstrate the applicability of the cell we use oxidation of carbon monoxide over an alumina-supported platinum powder catalyst as a model reaction while carrying out both in situ XAS and MS measurements. The possibility to perform XAS in fluorescence mode with low energy is also demonstrated on alumina supported silver and palladium powder catalysts as are transmission XAS on a platinum-alumina monolith catalyst.

\section{EXPERIMENTAL SECTION}

\section{A. Design criteria and description of the in situ} sample environment reaction cell

As mentioned already, numerous reaction cells with different designs have been reported previously. The main driver for us is to make a cell available at the MAX IV Laboratory, Lund, that can meet some of the needs we have come across during experimental sessions at synchrotrons. From these needs we have defined a number of design criteria that should be fulfilled. The reaction cell should be robust and easy to use in terms of sample loading and mounting at the experimental station both in our home laboratories and at different beamlines, particularly at beam lines I711 and I811 at the MAX IV Laboratory. It should allow for XAS in both transmission and fluorescence mode as well as X-ray diffraction in situ measurements of primarily solids. The solids could be in the form of powders, small pellets or coated monoliths. To realize this, it should permit XAS measurements with $\mathrm{X}$-rays in a fairly broad energy range starting at around $3 \mathrm{keV}$. The catalytic reactor should be of plug-flow type wherein the sample temperature and gas environment surrounding the sample should be accurately controlled. The effluent stream should be easily accessible by proper analytics, e.g., mass spectrometry.

With these criteria in mind we arrived at the design depicted in Figure 1, which shows a three-dimensional schematic of the individual parts as well as the assembled reaction cell. The cell design is similar to a previously reported cell [22] but is here modified and demonstrated to be useful also for, as an example, lower X-ray energies. The stainless steel reaction cell consists of a back and front plate (P1 and P2), a reactor block (R) and back and front X-ray transparent windows (W1 and W2), which are all assembled together with screws. The reaction cell $(\mathrm{P} 1+\mathrm{W} 1+\mathrm{R}+\mathrm{W} 2+\mathrm{P} 2)$ is then mounted, by use of six screws, on a stainless steel holder $(\mathrm{H})$ that has both an internal heating and cooling system. The heating system is simply a resistively heated wire that is 


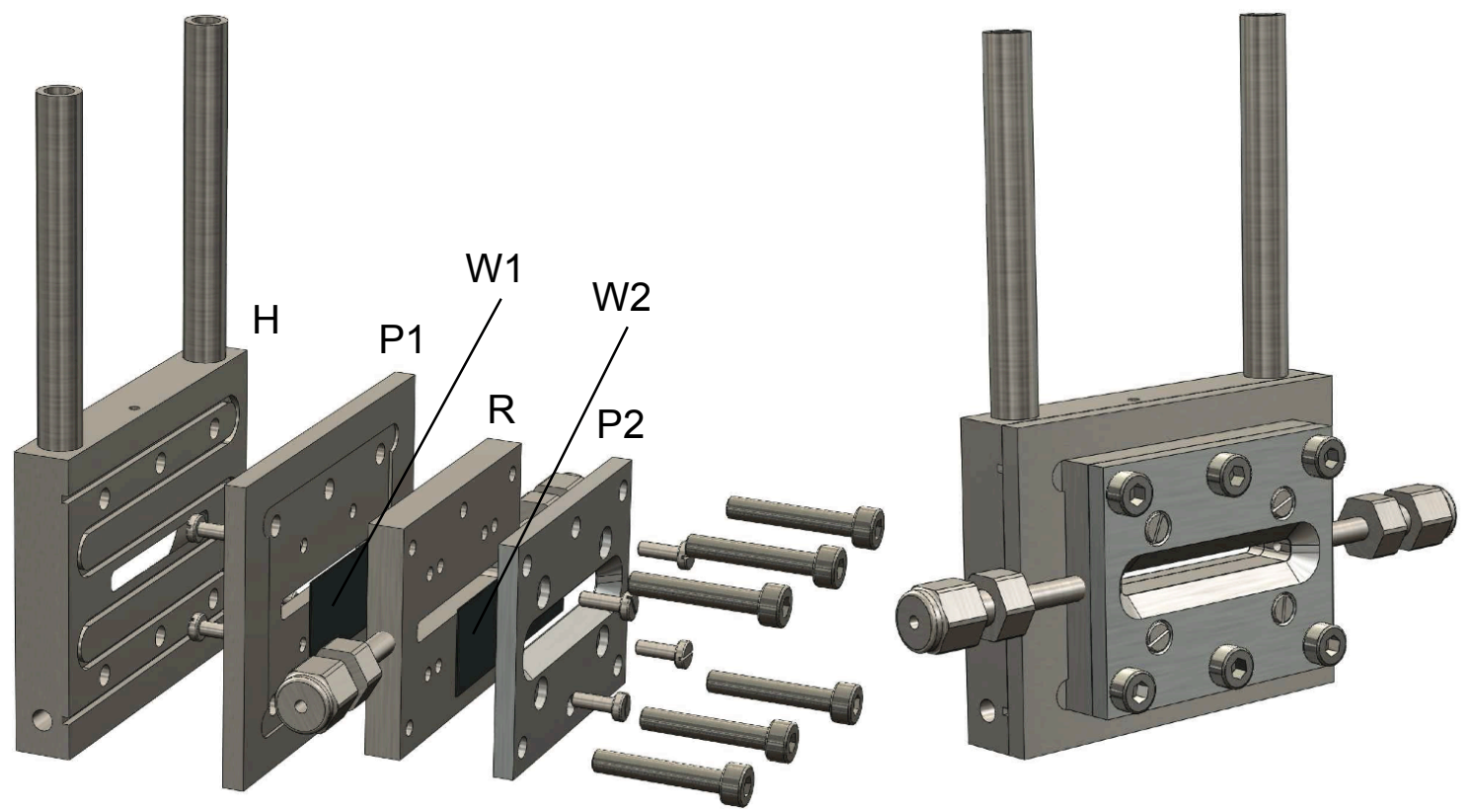

FIG. 1: Three-dimensional schematics of the reactor cell and the assembled model.

placed in the prefabricated track in the holder. For lowtemperature experiments cooling through circulation of a cooling media inside the body of the holder is possible. The temperature of the holder is measured by a thermocouple placed inside the channel on top of the main body of the holder and used for temperature control by use of a temperature regulator. The reaction block is mounted between the back and front plates. The main purpose of using P1 and P2 is to clamp the X-ray transparent windows and to allow for easy mounting/dismounting of the reaction cell on the holder at the beamline when changing sample. The $\mathrm{P} 1$ and $\mathrm{P} 2$ both have a deliberately grooved surface on the sides that are in contact with the X-ray transparent windows as to facilitate proper clamping of the windows. The P1 and P2 are both pinched to the reaction cell by four screws. The material (element, thickness, structure) to be used for the X-ray transparent windows needs to be considered carefully as to be sufficiently transparent to X-rays, chemically inert, temperature resistant and mechanically robust. The most common materials used are foils of aluminum, graphite or Kapton ${ }^{\circledR}$. The latter is a high temperature resistant plastic. In the present in situ measurements we use carbon foils with either 20 or $200 \mu \mathrm{m}$ thickness. The actual reaction block has a slit with the dimensions $17.0 \times 3.0$ $\times 5.0 \mathrm{~mm}$ (length $\times$ height $\times$ width) wherein the sample is positioned between two pieces of quarts wool. The sample volume can be adjusted by using more or less quartz wool. Also, in principle, the width of the sample bed can be varied by use of reactor blocks with different thickness. For example ranging between, say, one and five $\mathrm{mm}$ proper X-ray absorbance for different samples can be achieved. Another more common approach is to dilute the sample with an appropriate diluent. Finally, the gas inlet/outlet consists of standard 1/16" Swagelok connections for easy mounting of gas lines at the beamline.

\section{B. Feed gas delivery system and effluent gas analytics}

Studies of solid catalysts under operating conditions need a versatile feed gas delivery system to ensure a gas feed that is well-controlled and variable on demand. In the present case a gas delivery system based on commercially available components was constructed. Basically, five Bronkhorst mass flow controllers (MFC) are assembled on a common main body, the so-called Bronkhorst SMS system, and each MFC is controlled from a computer via a Labview interface. The effluent gas is analyzed on-line with a portable Pfeiffer Prisma mass spectrometer mounted on a Pfeiffer HiCube pump station. The gas inlet system to the mass spectrometer consists of a modified vacuum leak valve. By welding $1 / 16$ " standard Swagelok conectors as inlet/outlet on the leakage valve, the effluent gas is passed through the small chamber in the valve and over the actual leakage into the main chamber. This arrangement allows for rapid transport of gas into the analysis chamber and thus measurements with rather high time resolution (less than one second). It is a mechanically robust solution as compared to the more sensitive capillary-based gas inlets. However, in the cases with sticky gas components the gas lines need to be heated and depending on the stability of the gas components to be analyzed there may be a risk of decomposition/reaction of the sample gas before the actual composition analysis. Hence, heated quartz capillary-based 
systems may be more appropriate as such are chemically more inert and usually also more resistant towards sticky components.

\section{Catalytic systems and XAS measurements}

To demonstrate the applicability of the sample environment reaction cell, in situ XAS measurements were performed at beam line I811 at MAX IV Laboratory, Lund [23]. The $\mathrm{Pt} \mathrm{L}_{I I I}$ edge for $\mathrm{Pt} / \mathrm{Al}_{2} \mathrm{O}_{3}$ powder catalyst was measured in transmission mode during catalytic oxidation of carbon monoxide at $300^{\circ} \mathrm{C}$. During these experiment the oxygen concentration was changed stepwise while the $\mathrm{CO}$ feed and total flow were kept constant. To show the performance of the cell in fluorescence mode the XANES spectra for $\mathrm{Pd}_{I I I}$ and $\mathrm{Ag} \mathrm{L}_{I I I}$ edges were measured for a $\mathrm{Pd} / \mathrm{Al}_{2} \mathrm{O}_{3}$ and $\mathrm{Ag}-\mathrm{Al}_{2} \mathrm{O}_{3}$ powder catalyst, respectively. These measurements were performed both ex situ, i.e., with the sample attached onto a Kapton tape, and in situ in the reaction cell.

\section{RESULTS AND DISCUSSION}

\section{A. Temperature management}

To achieve high quality kinetic and structural data it is critical to ensure a precise temperature management of the sample. In fact, to achieve high quality kinetic data alone, the sample bed should preferably be isothermal so to facilitate more straightforward correlation of the global kinetic data with the amount of catalyst. Elimination of temperature gradients within the sample is however not straightforward. For example commercially available reaction cells for infrared spectroscopy often suffers from sample temperature variations and the temperature of the probed volume can deviate significantly from the set temperature [24]. With this in mind we made a comparison of the set temperature as measured in the holder and the temperature of the sample bed measured with another thermocouple. It was found that the two temperatures correlated well in the interval $25-500^{\circ} \mathrm{C}$. The pairwise values for the measured temperatures (in ${ }^{\circ} \mathrm{C}$ ) in the holder and sample are $(22.3,22.2),(47.7,47.5)$, $(101.1,102.3), \quad(157.6,157), \quad(207.4,206), \quad(259.7,256)$, $(307.3,304), \quad(356,350), \quad(405.3,399), \quad(454,446)$ and $(504,496)$. These data together with a linear fit, which can be used for temperature calibration, is plotted in Figure 2. Furthermore no significant temperature gradients along (axially) the sample bed could be measured.

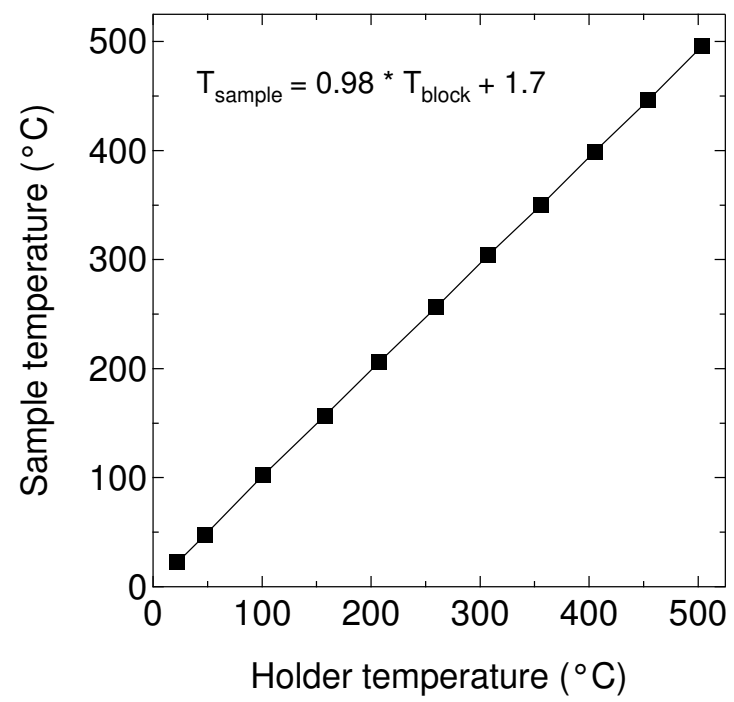

FIG. 2: Sample temperature versus holder (part H in Figure 1) temperature at nearly stationary conditions.

B. In situ transmission XAS measurements of the $\mathrm{Pt} \mathrm{L}_{I I I}$ edge of a $4 \% \mathrm{Pt} / \mathrm{Al}_{2} \mathrm{O}_{3}$ powder catalyst

The first example of the applicability of the reaction cell is an in situ XAS measurement of the $\mathrm{Pt} \mathrm{L}_{I I I}$ edge for a $4 \% \mathrm{Pt} / \mathrm{Al}_{2} \mathrm{O}_{3}$ powder catalyst under mild annealing in $\mathrm{Ar}$ at $150^{\circ} \mathrm{C}$. The resulting complete $\mathrm{X}$-ray absorption spectrum and XANES region of the spectrum are shown in Figure 3a and b respectively. The spectrum shows typical features for the $\mathrm{Pt} \mathrm{L}_{I I I}$ edge, with a clear absorption edge (white-line) at around $11.56 \mathrm{keV}$. This corresponds well with previously reported spectra for the $\mathrm{Pt} \mathrm{L}_{I I I}$ edge [20]. As can be seen in panel a, the reaction cell admits recording of the spectrum over a sufficiently broad energy range for EXAFS analysis although not explicitly carried out here. The XANES region is well captured and the spectral quality should allow for detailed analysis of the white-line and possible pre-edges in case of other elemental compositions.

The second example is shown in Figure 4 and is an in situ XANES measurement of the $\mathrm{Pt}_{I I I}$ edge during oxidation of 2.0 vol.- $\% \mathrm{CO}$ over the same $4 \% \mathrm{Pt} / \mathrm{Al}_{2} \mathrm{O}_{3}$ powder catalyst. In this measurement the sample was first exposed to 2.0 vol.-\% CO and a XANES spectrum (black spectrum at the bottom of Figure 4) was recorded. Here the catalyst is reduced by $\mathrm{CO}$ and the intensity of the white-line corresponds to platinum in a reduced state. This state is indicated by a dashed horizontal line for reference. Thereafter, upon introducing an excess of oxygen (5 vol.- \%), a catalytic ignition of the $\mathrm{CO}$ oxidation reaction is initiated and $\mathrm{CO}_{2}$ is formed as measured by mass spectrometry (not shown). All spectra corresponding to an active catalyst forming $\mathrm{CO}_{2}$ are colored red in Figure 4. During the catalytic ignition of the $\mathrm{CO}$ oxidation the surface changes from being completely covered by ad- 

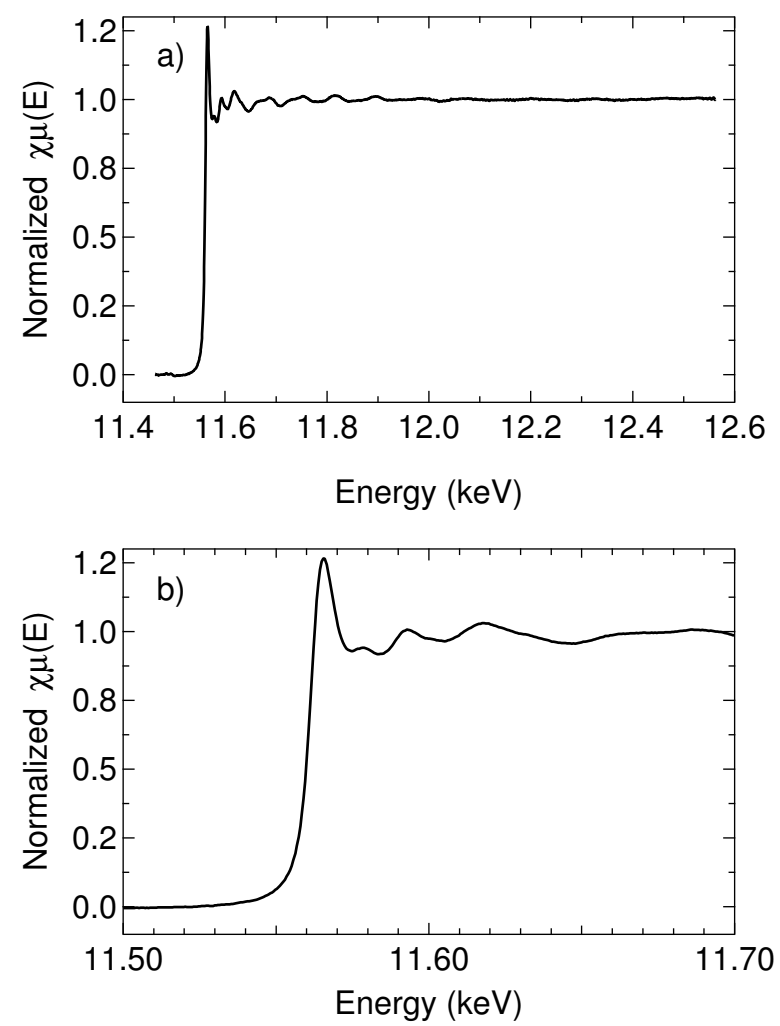

FIG. 3: In situ X-ray absorption spectra for $\mathrm{Pt}_{\mathrm{L}_{I I I}}$ edge obtained in transmission mode for a $4 \% \mathrm{Pt} / \mathrm{Al}_{2} \mathrm{O}_{3}$ powder catalyst under mild annealing in $\mathrm{Ar}$ at $150^{\circ} \mathrm{C}$. (a) complete Xray absorption spectrum and (b) X-ray near edge structure (XANES) region of the spectrum.

sorbed CO (reduced state) to a state with predominantly chemisorbed $\mathrm{O}$, as the adsorption of oxygen is dissociative at the temperatures of the experiment. The high oxygen coverage induces an oxidation of the surface of the platinum particles [25]. This can be seen as a slight increase of the white-line intensity (as compared to the reference) in line with previous studies [26]. The feed oxygen concentration was then decreased in steps to 2.5, 1.25 and 0.75 and 0 vol.- $\%$. The resulting XANES spectra are nearly unchanged until the lowest oxygen concentration is fed. Here the white-line intensity is close to that for the reduced state and although the catalyst is still active forming $\mathrm{CO}_{2}$, this reflects that $\mathrm{CO}$ has started to build up on the catalyst surface reducing the oxide and the catalytic reaction is close to extinction. It is likely so that dwelling the experiment at this $\mathrm{CO} / \mathrm{O}_{2}$ mixture will result in an extinction. Finally, however, when oxygen is removed from the feed the reaction, of course, stops and the platinum is completely $\mathrm{CO}$ covered and reduced to the same level as at the start of the experiment.
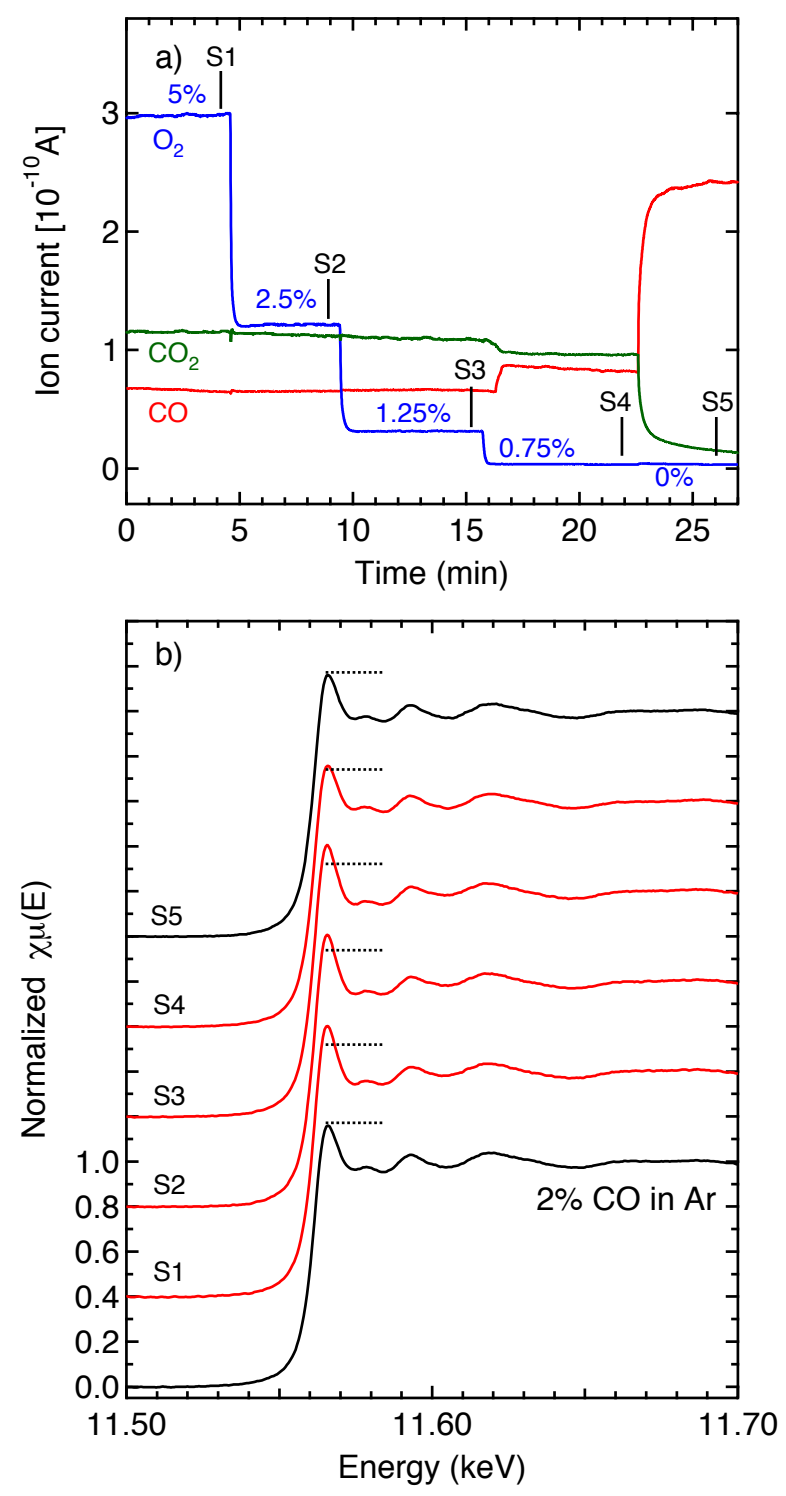

FIG. 4: Oxidation of $2 \% \mathrm{CO}$ over a $4 \% \mathrm{Pt} / \mathrm{Al}_{2} \mathrm{O}_{3}$ powder catalyst during stepwise decrease of the oxygen concentration from 5 to $0 \%$ at $300^{\circ} \mathrm{C}$. Argon was used as carrier gas and the total flow was $50 \mathrm{Nml} / \mathrm{min}$. Panel a) shows the outlet mass spectrometer responses for $\mathrm{CO}(\mathrm{m} / \mathrm{z} 28), \mathrm{O}_{2}(\mathrm{~m} / \mathrm{z} 32)$ and $\left.\mathrm{CO}_{2}(\mathrm{~m} / \mathrm{z}) 44\right)$ while panel $\left.\mathrm{b}\right)$ shows the in situ X-ray near edge structure (XANES) region of the $\mathrm{Pt} \mathrm{L}_{I I I}$ edge obtained in transmission mode. The dashed lines indicates the maximum height of the white line for the reduced sample. Red/black spectrum denotes oxygen/oxygen-free conditions and S1 to S5 indicates the time for recording of the spectra.

\section{In situ fluorescence $\mathrm{XAS}$ for $\mathrm{Pd} \mathrm{L}_{I I I}$ and $\mathrm{Ag}$ $\mathrm{L}_{I I I}$ edges for $\mathrm{Pd} / \mathrm{Al}_{2} \mathrm{O}_{3}$ and $\mathrm{Ag}-\mathrm{Al}_{2} \mathrm{O}_{3}$ catalysts}

The transmission measurements of the $\mathrm{Pt} \mathrm{L}_{I I I}$ edge shown so far are relatively straightforward as the relevant $\mathrm{X}$-ray energy is sufficiently high to penetrate the reaction cell and the $\mathrm{Pt} / \mathrm{Al}_{2} \mathrm{O}_{3}$ sample. To measure XANES at 


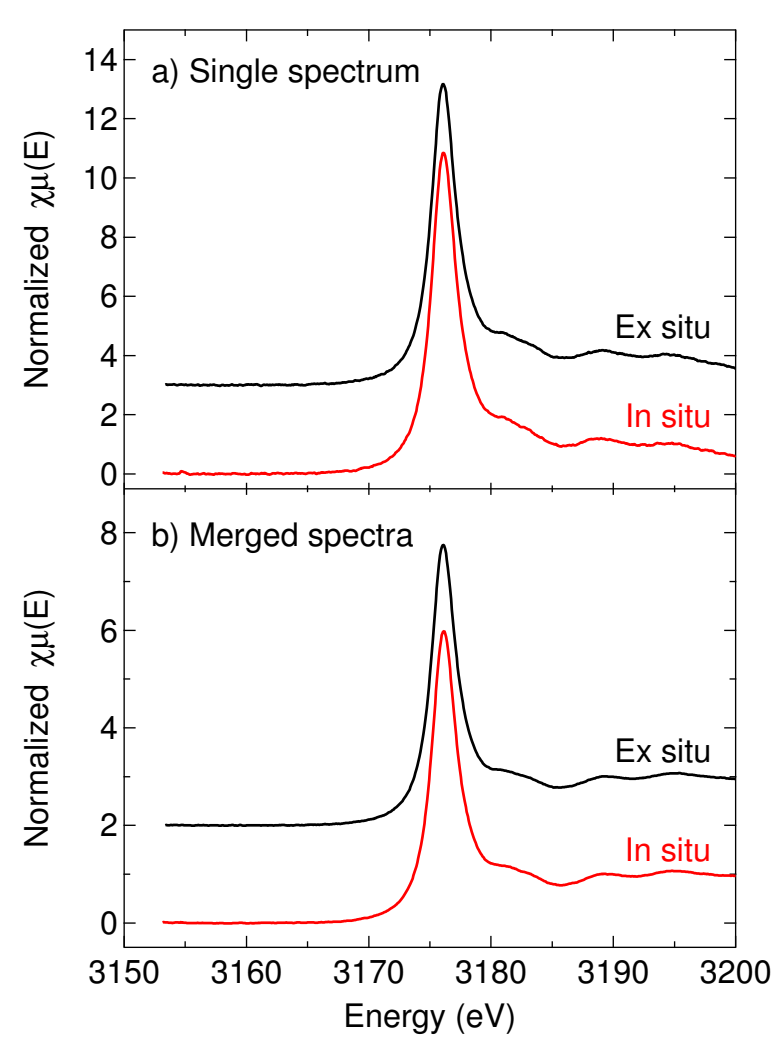

FIG. 5: X-ray near edge structure (XANES) region of the Pd $\mathrm{L}_{I I I}$ edge obtained in fluorescence mode for a $2 \% \mathrm{Pd} / \mathrm{Al}_{2} \mathrm{O}_{3}$ powder catalyst positioned on a Kapton tape and inside the in situ reaction cell which is equipped with thin $(20 \mu \mathrm{m})$ carbon windows. (a) single spectrum and (b) merged spectrum composed of five individual spectra. The black curves have been shifted for clarity.

the $\mathrm{Pd} \mathrm{L}_{I I I}$ and $\mathrm{Ag} \mathrm{L}_{I I I}$ edges for $\mathrm{Pd} / \mathrm{Al}_{2} \mathrm{O}_{3}$ and $\mathrm{Ag}$ $\mathrm{Al}_{2} \mathrm{O}_{3}$ catalysts, respectively, is however more difficult as the relevant energy is close to $3 \mathrm{keV}$. Thus such measurements typically requires experiments in fluorescence mode and the choice of X-ray transparent windows is more delicate as well as the elimination of air between the reaction cell and the detector. In the present case we used thin $(20 \mu \mathrm{m})$ carbon foil as windows. Also, the sample bed was reduced to about $2 \mathrm{~mm}$ thickness. As a common practice, the sample cell was rotated $45^{\circ}$ from the incident beam and the PIPS detector was positioned also $45^{\circ}$ relative the cell.

The XANES spectra for the $\mathrm{L}_{I I I}$ edges of $\mathrm{Pd}$ and $\mathrm{Ag}$ are displayed in Figure 5 and 6, respectively. The black spectra recorded outside the reaction cell, i.e., with the sample attached onto a Kapton tape, serves as a reference. The single spectra and merged (average) spectra are displayed in the top and bottom panels, respectively. The spectral quality is clearly sufficient for proper XANES analysis of both the Pd and Ag based samples. The spectral features of the $\mathrm{L}_{I I I}$ edges are in line with previously reported data for both Pd catalysts [27] and Ag oxides [28]. Although these measurements were car-

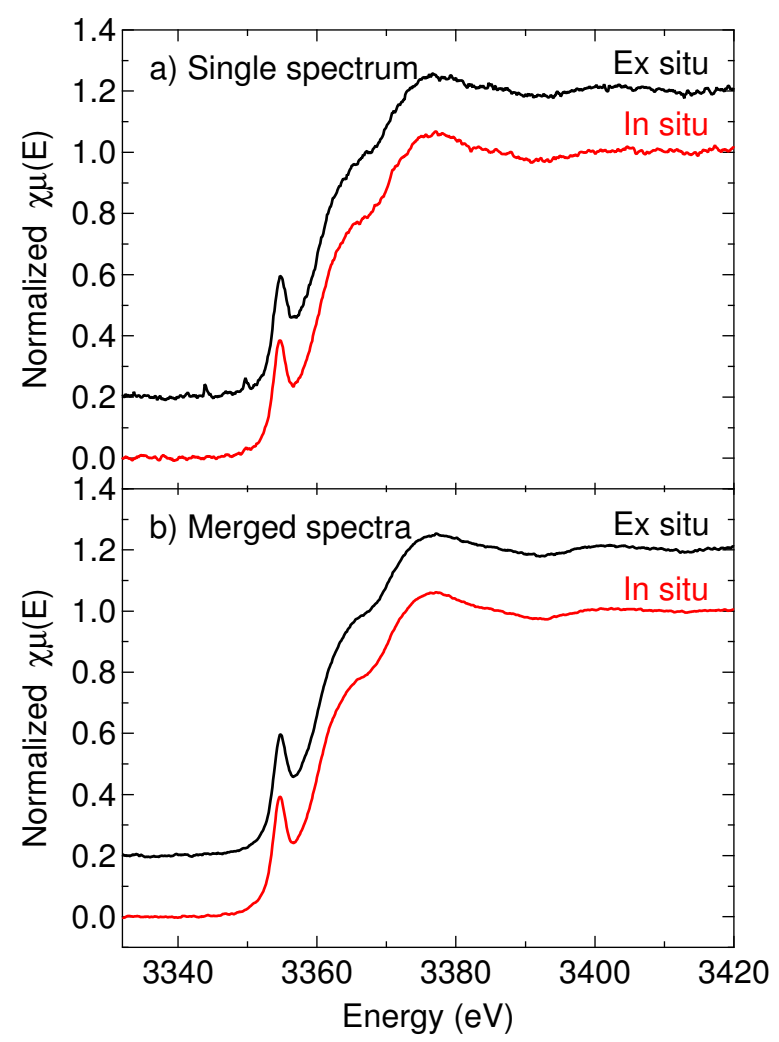

FIG. 6: X-ray near edge structure (XANES) region of the Ag $\mathrm{L}_{I I I}$ edge obtained in fluorescence mode for a $2 \% \mathrm{Ag}-\mathrm{Al}_{2} \mathrm{O}_{3}$ powder catalyst positioned on a Kapton tape and inside the in situ reaction cell which is equipped with thin $(20 \mu \mathrm{m})$ carbon windows. (a) single spectrum and (b) merged spectrum composed of ten individual spectra. The black curves have been shifted for clarity.

ried out under stationary air conditions at room temperature feeding of a reaction mixture through the reaction cell is not expected to significantly influence the quality of the spectra and thus these results demonstrate that relevant in situ experiments are possible also in fluorescence mode.

\section{Transmission XAS employed to structured catalysts}

In principle the design of the reaction cell permits measurements on small structured reactors such as catalyst pellets or coated monoliths provided that the type and concentration of the element to be studied absorbs X-rays sufficiently well. A general challenge with such samples, however, is the presence of several additional elements that likely contribute both to absorbance and scattering of the X-rays, making the XAS measurement difficult in terms of signal-to-noise ratio and spectral quality over the energy range needed for reliable analysis. The example to be used here is again the transmission XAS measurement on the $\mathrm{Pt} \mathrm{L}_{I I I}$ edge but in this case for a three by 

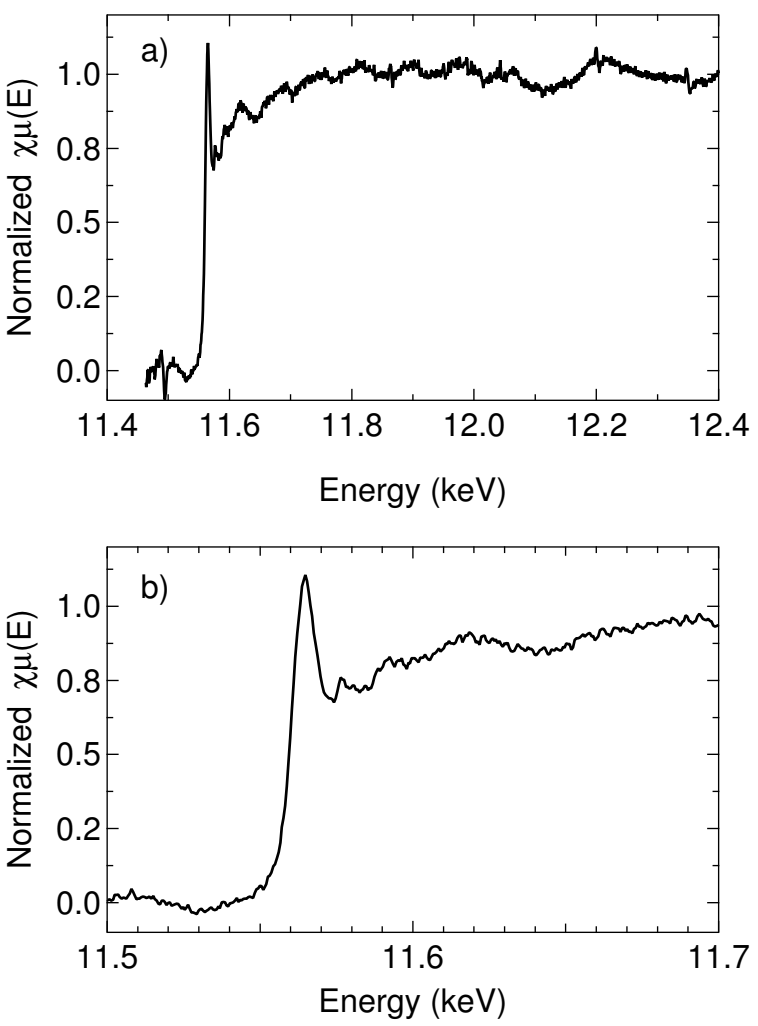

FIG. 7: Ex situ x-ray absorption spectrum (a) and the x-ray near edge structure (XANES) region (b) of the $\mathrm{Pt} \mathrm{L}_{I I I}$ edge for a $\mathrm{Pt} / \mathrm{Al}_{2} \mathrm{O}_{3}$ monolith catalyst.

three channel cordierite $\left(2 \mathrm{Al}_{2} \mathrm{O}_{3} \cdot 5 \mathrm{SiO}_{2} \cdot 2 \mathrm{MgO}\right)$ monolith structure where the channel walls are coated with a thin layer of the $4 \% \mathrm{Pt} / \mathrm{Al}_{2} \mathrm{O}_{3}$ powder catalyst. This represents a typical car exhaust catalyst but finds relevance also in a broader perspective, e.g., catalysts for production of chemicals and energy conversion processes. Figure $7 \mathrm{a}$ and $\mathrm{b}$ shows the complete XAS spectrum and the XANES region of the spectrum, respectively. As can be seen EXAFS analysis is not applicable as the post-edge region is too distorted for this sample. However, the measurement of the white-line may be acceptable and, keeping the challenges and relevance in mind, useful information can be achieved although improved background adjustment and normalization would be desirable.

Finally we comment on the possibility to carry out in situ X-ray diffraction (XRD) studies and spatially resolved measurements. Depending on the conditions for a certain X-ray measurement, e.g., X-ray energy and spot size, the design of the reaction cell allows for in situ XRD as well as axially resolved XAS and XRD in situ studies. XRD is a strong complementary techniques to XAS as the long-range order in materials can be determined. With the recent development of, particularly, high-energy XRD methods that have been used to study both ideal surfaces [29, 30] and powders [21], XRD is becoming more widely used as an in situ technique, especially within catalysis research. Even if spatially resolved measurements are not the primary goal, it comes as a positive side effect thanks to the design of the cell. Axially resolved measurements can be an important discretization of the sample bed to understand for example partial oxidation reactions where the chemical state and structure varies along the bed as reactants/products are consumed/formed [31].

\section{CONCLUDING REMARKS}

In this work we have developed an easy-to-use sample environment reaction cell for in situ XAS studies of powders and small structured samples, e.g., pellets and monolith catalysts. We have shown that the reaction cell can be used for XAS in both transmission and fluorescence mode and demonstrated the in situ capabilities by measuring the $\mathrm{Pt} \mathrm{L}_{I I I}$ edge for a $\mathrm{Pt} / \mathrm{Al}_{2} \mathrm{O}_{3}$ powder catalyst under catalytic oxidation of carbon monoxide. The reaction cell is cheep to produce and thus one can with advantage, during an experimental session, use multiple reaction cells so that one is used for measurements while another one is loaded with a new sample.

\section{ACKNOWLEDGEMENTS}

This work is done within the Röntgen-Ångström Collaborations Catalysis on the atomic scale, Swedish Research Council (349- 2011-6491) and Time-resolved in situ methods for design of catalytic sites within sustainable chemistry, Swedish Research Council (349-2013567 ), and partly within the Competence Centre for Catalysis, which is hosted by Chalmers University of Technology and financially supported by the Swedish Energy Agency and the member companies AB Volvo, ECAPS AB, Haldor Topsøe A/S, Scania CV AB, Volvo Car Corporation $\mathrm{AB}$ and Wärtsilä Finland $\mathrm{Oy}$.
[1] B. M. Weckhuysen, In-Situ Spectroscopy of Catalysts (American Scientific Publishers, 2004).

[2] T. M. Letcher and J. L. Scott, Materials for a Sustainable Future (The Royal Society of Chemistry, Cambridge, United Kindom, 2012).

[3] D. C. Koningsberger, B. L. Mojet, G. E. van Dorssen, and D. E. Ramaker, Top. Catal. 10, 143 (2000).

[4] M. A. Newton and W. van Beek, Chem. Soc. Rev. 39, 4845 (2010).

[5] S. Bordiga, E. Groppo, G. Agostini, J. A. van Bokhoven, and C. Lamberti, Chem. Rev. 113, 1736 (2013).

[6] B. S. Clausen and H. Topsøe, Catal. Today 9, 189 (1991). 
[7] B. S. Clausen, L. Gråbæk, G. Steffensen, P. L. Hansen, and H. Topsøe, Catal. Lett. 20, 23 (1993).

[8] B. S. Clausen, Catal. Today 39, 293 (1998).

[9] F. W. H. Kampers, T. M. J. Maas, J. van Grondelle, P. Brinkgrave, and D. C. Koningsberger, Rev. Sci. Instrum. 60, 2635 (1989).

[10] G. Sankar, J. M. Thomas, F. Rey, and G. N. Greaves, J. Chem. Soc. Chem. Commun. p. 2549 (1995).

[11] G. Meitzner, S. R. Bare, D. Parker, H. Woo, and D. A. Fischer, Rev. Sci, Instrum. 69, 2618 (1998).

[12] J. F. Odzak, A. M. Argo, F. S. Lai, B. C. Gates, K. Pandya, and L. Feraria, Rev. Sci, Instrum. 72, 3943 (2001).

[13] J.-D. Grunwaldt, M. Caravati, S. Hannamann, and A. Baiker, Phys. Chem. Chem. Phys. 6, 3037 (2004).

[14] S. Schneider, J. X-ray Sci. Technol. 8, 221 (2000).

[15] A. M. J. van der Eerden, J. A. van Bokhoven, A. D. Smith, and D. C. Koningsberger, Rev. Sci, Instrum. 71, 3260 (2000).

[16] S. R. Bare, G. E. Mickelson, F. S. Modica, A. Z. Ringwelski, and N. Yang, Rev. Sci. Instrum. 77, 023105 (2006).

[17] G. L. Chiarello, M. Nachtegaal, V. Marchionni, L. Quaroni, and D. Ferri, Rev. Sci. Instrum. 85, 074102 (2014).

[18] B. S. Clausen, G. Steffensen, B. Fabius, J. Villadsen, R. Feidenhans'l, and H. Topsøe, J. Cata. 132, 524 (1991).

[19] M. A. Newton, Top. Catal. 52, 1410 (2009).

[20] E. Becker, , P.-A. Carlsson, L. Kylhammar, M. A. Newton, and M. Skoglundh, J. Phys. Chem. C 115, 944 (2011).

[21] D. Bounechada, S. Fouladvand, L. Kylhammar, T. Pingel, E. Olsson, M. Skoglundh, J. Gustafson, M. D.
Michiel, M. A. Newton, and P.-A. Carlsson, Phys. Chem. Chem. Phys. 15, 8648 (2013).

[22] S. Hannemann, M. Casapu, J.-D. Grünwaldt, P. Haider, P. Trüssel, A. Baiker, and E. Welter, J. Synchrotron Rad. 14, 345 (2007).

[23] S. Carlson, M. Clausen, L. Gridneva, B. Sommarin, and C. Svensson, J. Synchrotron. Rad. 13, 359 (2006).

[24] H. Li, M. Rivallan, F. Thibault-Starzyk, A. Travert, and F. C. Meunier, Phys. Chem. Chem. Phys. 15, 7321 (2013).

[25] P.-A. Carlsson, V. P. Zhdanov, and B. Kasemo, Appl. Surf. Sci. 239, 424 (2005).

[26] P.-A. Carlsson, L. Österlund, P. Thormählen, A. Palmqvist, E. Fridell, J. Jansson, and M. Skoglundh, J. Catal. 226, 422 (2004).

[27] K.-I. Shimizu, Y. Kamiya, K. Osaki, H. Yoshida, and A. Satsuma, Catal. Sci. Technol. 2, 767 (2012).

[28] P. Behrens, S. A $\beta$ mann, U. Bilow, C. Linke, and M. Jansen, Z. anorg. allg. Chem. 625, 111 (1999).

[29] J. Gustafson, M. Shipilin, C. Zhang, A. Stierle, U. Hejral, U. Ruett, O. Gutowski, P.-A. Carlsson, M. Skoglundh, and E. Lundgren, Science 343, 758 (2014).

[30] M. Shipilin, U. Hejral, E. Lundgren, L. R. Merte, C. Zhang, A. Stierle, U. Ruett, O. Gutowski, M. Skoglundh, P.-A. Carlsson, et al., Surf. Sci. 630, 229 (2014).

[31] C. G. Schroer and J.-D. Grunwaldt, Spatially Resolved XRay Absorption Spectroscopy (John Wiley \& Sons, Chichester, England, 2013). 